\title{
Enhancement of Blood Cholesterol Level Relating to Edible Reused Cooking Oil Uptake in White Experimental Albino Rats
}

\author{
Mutaz Mohamed Ahmed Elshiekh \\ Ahfad Center for Science and Technology (ACST), Ahfad University for Women, Khartoum, Sudan \\ Email address: \\ elshiekhmutaz@gmail.com \\ To cite this article: \\ Mutaz Mohamed Ahmed Elshiekh. Enhancement of Blood Cholesterol Level Relating to Edible Reused Cooking Oil Uptake in White \\ Experimental Albino Rats. American Journal of Applied Chemistry. Vol. 8, No. 2, 2020, pp. 55-62. doi: 10.11648/j.ajac.20200802.12
}

Received: December 7, 2019; Accepted: January 6, 2020; Published: May 28, 2020

\begin{abstract}
Reusing cooking oil in food preparation, especially during deep-frying is a common practice to save costs. Repeated heating of the oil accelerates oxidative degradation of lipids leading to severe changes in lipid profile of the blood and forming hazardous reactive oxygen species which depletes the natural antioxidant contents of the cooking oil leading to pathologies such as hypertension, diabetes and vascular inflammation. The main objective of this work is to investigate the effect of the reused edible cooking oil uptake with the plasma cholesterol level in some experimental animals. Twenty adult male swiss albino (SWR) rats, weighing 120-200g body weight were housed within the premises of the medicinal and aromatic plant research institutes, national center for research Khartoum. They were randomized to one of the following experimental groups, with five animals per group: Group 1 the Normal group were administered normal diet (control group), Group 2 the experimental group were administered high-fat diet with low dose reused oil injection, Group3 the experimental group were administered high-fat diet with high dose reused oil injection, Group4 the experimental group were administered high -fat diet (disease group). Randomly fasting blood cholesterol level was done in 20 rats to identify the level of cholesterol before the administration of special diet that contain high saturated fat and cholesterol powder to elevate the level of cholesterol in albino rats. Rats of group two were injected with $1.5 \mathrm{ml} / \mathrm{kg}$ reused oil as a low dose and rats of group three will be injected with 3.0 $\mathrm{ml} / \mathrm{kg}$ reused oil as a high dose. blood sampling and cholesterol level determination were done once a week for each rat separately for four weeks. Concerning the average cholesterol level of group 1 rats, it showed a narrow range elevation for the consecutive four weeks respectively. Group 2 rats shows a considerable range of average cholesterol level elevation. For rats of group 3 we expect a significant average cholesterol level elevation starting from the fasting period up to the fourth week, as the rats of this group were injected with $3 \mathrm{ml} / \mathrm{kg}$ (considered as a high dose) reused oil in addition to the high cholesterol diet and this is exactly what we observed. The average cholesterol level of group 4 rats was moderately elevated.
\end{abstract}

Keywords: Cholesterol Level, Reused Oil, Albino Rats, Normal Group and Disease Group

\section{Introduction}

Fats and lipids are common components of food and may perform essential roles. Their types may be more important with regard to health and disease than their amount. New research has linked functional lipids to the prevention and treatment of many diseases.

\subsection{Lipids}

Lipids are molecules that can be extracted from biological tissue with a nonpolar solvent. Lipids are essential components of all living organisms. Lipids are water insoluble organic compounds. They are hydrophobic (nonpolar) or amphipathic (containing both nonpolar and polar regions). [1]

\subsection{Omega 3 and Omega 6 Fatty Acids}

Omega- 6 fatty acids (also referred to as $\omega-6$ fatty acids or $n-6$ fatty acids) are a family polyunsaturated fatty acids that have in common a final carbon-carbon double bond in the $n$ 6 position, that is, the sixth bond, counting from the methyl end. [2] 
Omega-3 fatty acids - also called $\omega-3$ fatty acids or $n-3$ fatty acids are polyunsaturated fatty acids (PUFAs) with a double bond $(\mathrm{C}=\mathrm{C})$ at the third carbon atom from the end of the carbon chain. Fatty acids, especially essential fatty acids, are gaining importance in poultry feeding systems not only for improving the health and productivity of birds, but also because of our health-conscious society that prefers properly balanced diets to minimize adverse health issues [3].
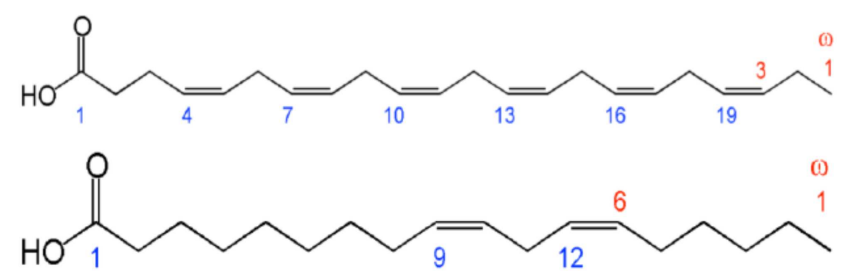

\subsection{Structure of Triglyceride}

A triglyceride (TG, triacylglycerol, TAG, or triacylglyceride) is an ester derived from glycerol and three fatty acids (tri- + glyceride). Triglycerides are the main constituents of body fat in humans and other animals, as well as vegetable fat. They are also present in the blood to enable the bidirectional transference of adipose fat and blood glucose from the liver, and are a major component of human skin oils.

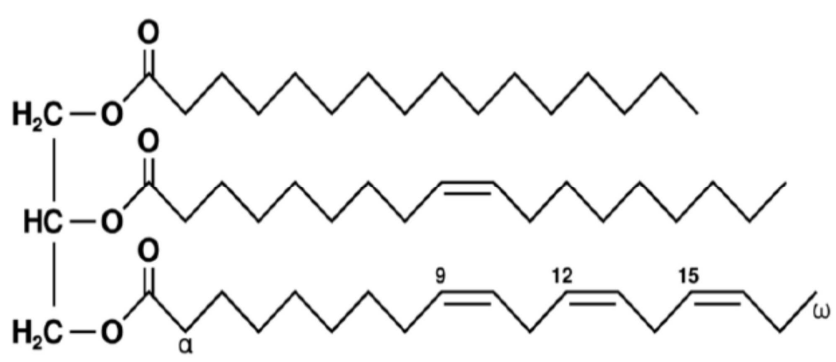

There are many different types of triglyceride, with the main division between saturated and unsaturated types. Saturated fats are "saturated" with hydrogen - all available places where hydrogen atoms could be bonded to carbon atoms are occupied. These have a higher melting point and are more likely to be solid at room temperature. Unsaturated fats have double bonds between some of the carbon atoms, reducing the number of places where hydrogen atoms can bond to carbon atoms. These have a lower melting point and are more likely to be liquid at room temperature [4].

\subsection{Cholesterol}

Cholesterol modulates the fluidity of mammalian cell membranes. It is also a precursor of the steroid hormones and bile salts. It is a sterol (has hydroxyl group at C-3). The fused ring system makes cholesterol less flexible than most other lipids.

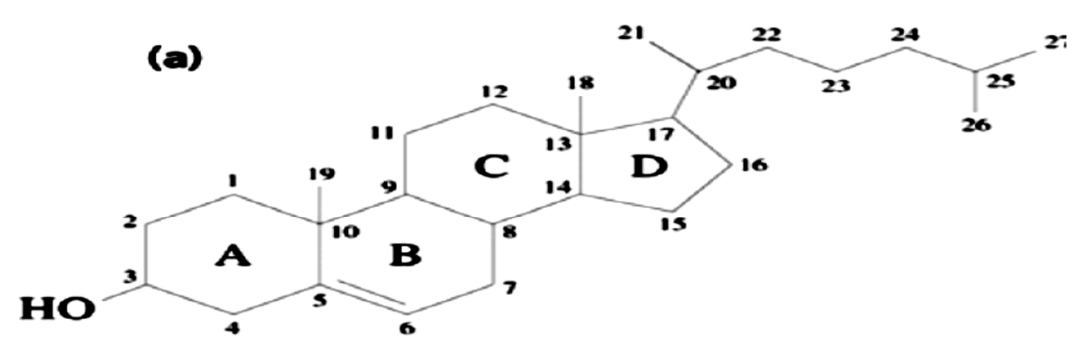

\subsubsection{Cholesterol esters}

Cholesterol is converted to cholesterol esters for cell storage or transport in blood. Fatty acid is esterified to C-3 $\mathrm{OH}$ of cholesterol. Cholesterol esters are very water insoluble and must be complexed with phospholipids or amphipathic proteins for transport. [5].

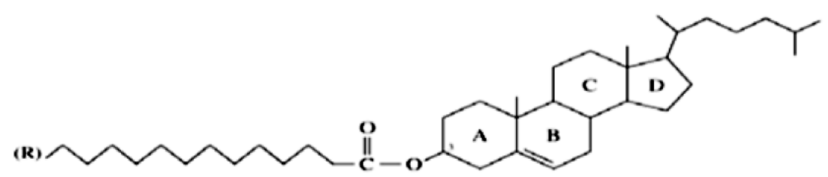

\subsubsection{Importance of Cholesterol}

1- Helping to make the outer coating of cells.

2- Making up the bile acids that work to digest food in the intestine.

3- Allowing the body to make Vitamin D and hormones, like estrogen in women and testosterone in men [6].

\subsection{Lipid Profile Test}

Your health care team can do a simple blood test to check your cholesterol levels. The test is called a lipid profile. The test measures several kinds of total cholesterol and its individual parts including triglycerides. Some doctors do another blood test that just checks total and HDL cholesterol [7].

\subsection{Complication of High Cholesterol on the Body}

Cholesterol moves through your bloodstream via lipoproteins. Low-density lipo proteins (LDL) and High density lipoproteins (HDL). Too much LDL and not enough HDL makes it more likely that the arteries will develop plaque that lead to coronary arteries narrow, it's harder for blood to make it through to the heart. If an area of plaque breaks open, it can result in a blood clot, which can block blood flow all together. This creates a great risk of having a heart attack. High cholesterol can create a bile imbalance, leading to gallstones Symptoms include abdominal pain, nausea, vomiting, and bloody stools.

\subsection{Some Diseases Related to High Blood Cholesterol Level}

\subsubsection{Coronary Heart Disease}

The main risk associated with high cholesterol is coronary 
heart disease (CHD). If the cholesterol is too high, it builds up on the walls of the arteries. Over time, this buildup is known as atherosclerosis. This condition causes arteries to become narrowed, and the narrowed blood vessels reduce blood flow to the heart. This can result in angina (chest pain) from not enough blood flow getting to the heart, or a heart attack in cases when a blood vessel is blocked completely and the heart muscle begins to die.

\subsubsection{Stroke}

A stroke occurs when a blood vessel that carries oxygen and nutrients to the brain becomes blocked or bursts. A stroke can result if the blood supply to the brain is reduced. When stroke occurs, part of the brain cannot get the blood and oxygen it needs, so it starts to die.

\subsubsection{Peripheral Arterial Disease}

High cholesterol also has been linked to peripheral arterial disease (PAD), which refers to diseases of blood vessels that are outside the heart and brain. In PAD, fat deposits build up along artery walls and affect blood circulation, mainly in arteries leading to the legs and feet. The arteries of the kidney can also be affected.

\subsubsection{Type 2 Diabetes}

Type 2 diabetes is another disease linked to high cholesterol because diabetes can affect the different cholesterol levels. Even if blood sugar control is good, people with diabetes tend to have increased triglycerides, decreased high-density lipoprotein (HDL), and sometimes increased low-density lipoprotein (LDL). This increases the likehood of developing atherosclerosis.

\subsubsection{High Blood Pressure}

High blood pressure (hypertension) and high cholesterol also are linked. When the arteries become hardened and narrowed with cholesterol plaque and calcium (atherosclerosis), the heart has to strain much harder to pump blood through them. As a result, blood pressure becomes abnormally high. [8]

\subsection{Sunflower Oil}

Sunflower oil is the non-volatile oil compressed from the seeds of sunflower (Helianthus annuls). Sunflower oil is commonly used in food as frying oil, and in cosmetic formulations as an emollient. The world's largest sunflower oil producers now are Ukraine, Russia and Argentina. [9]

\section{Method}

\subsection{General Methodology}

Twenty adult male Swiss albino (SWR) rats, weighing $120-200 \mathrm{~g}$ body weight were housed within the premises of the medicinal and aromatic plant research institutes, national center for research Khartoum. They were kept under good ventilation with 12 hours light and dark cycle. They were housed in the experiment animal laboratory of the institute. The animals were allowed acclimatize for five days having access to water and food. They were randomized to one of the following experimental groups, with five animals per group:

Group 1: Normal rats were administered normal diet (control group).

Group 2: Experimental group were administered high-fat diet and will be injected with low dose reused oil.

Group3: Experimental group were administered high-fat diet and will injected with high dose reused oil

Group4: Experimental group were administered high -fat diet (disease group).

Randomly fasting blood cholesterol level test was done in the 20 rats to identify the level of cholesterol before the administration of special diet that contain high saturated fat and cholesterol powder to elevate the level of cholesterol in albino rats.

Rats of group 2 will be injected individually with 1.5 $\mathrm{ml} / \mathrm{kg}$ reused oil as low does and rats of group 3 will be injected with $3.0 \mathrm{ml} / \mathrm{kg}$ reused oil as high does. blood sampling and cholesterol level determination were done once a week for each rat separately. [10]

\subsection{Feeding the Animal}

The animals were fed by cholesterol -enriched high fat diet for four weeks. The mixture consists of $50 \mathrm{ml}$ of natural Ghee and $9.6 \mathrm{gm}$ of cholesterol powder (stabilizer 95\%). Cholesterol powder was added gradually to the ghee with continuous mixing with glass rod until homogenous solution was obtained. This gave a fatty dietary formula with concentration of $2 \mathrm{gm} / 10 \mathrm{ml}$ ghee. The rats were received the mixture according to weight for four weeks. [11]

\subsection{Blood Collection}

The blood was collected in heparin zed tube from rats in each group and centrifuged at $3000 \mathrm{rpm}$ and the plasma was collected. Plasma level of total cholesterol was determined.

\subsection{Total Cholesterol Determination}

This was determined according to modified enzymatic method of Trinder (1969); the method is based on the ability of all cholesterol ester present in plasma to quantitatively hydrolyze into free cholesterol and fatty acid by cholesterol esterse. In the presence of oxgen, free cholesterol is then oxidized by cholesterol oxidase to cholest-4-ene-3-one and hydrogen peroxide $(\mathrm{H} 2 \mathrm{O} 2)$. The $\mathrm{H} 2 \mathrm{O} 2$ reacts with phenol and 4- amino phenazone in the presence of peroxidase to form an o-quino eimine dye. The intensity of the color form is proportional to the cholesterol concentration in the sample with maximum absorption at $500 \mathrm{~nm}$. [12] 


\section{Results}

Table 1. Cholesterol level in $\mathrm{mg} / \mathrm{dl}$ for the 20 rats during the fasting period at zero time.

\begin{tabular}{|c|c|}
\hline Number of Rats & Total. Cholesterol(mg/dl) \\
\hline \multicolumn{2}{|l|}{ Group(1) } \\
\hline 1 & 75 \\
\hline 2 & 78 \\
\hline 3 & 70 \\
\hline 4 & 73 \\
\hline 5 & 70 \\
\hline \multicolumn{2}{|l|}{ Group(2) } \\
\hline 2 & 82 \\
\hline 3 & 75 \\
\hline 4 & 80 \\
\hline 5 & 68 \\
\hline \multicolumn{2}{|l|}{ Group(3) } \\
\hline 1 & 69 \\
\hline 2 & 74 \\
\hline 5 & 76 \\
\hline \multicolumn{2}{|l|}{ Group(4) } \\
\hline 1 & 68 \\
\hline 2 & 86 \\
\hline 3 & 78 \\
\hline 4 & 75 \\
\hline 5 & 66 \\
\hline
\end{tabular}

Table 2. Cholesterol level in $\mathrm{mg} / \mathrm{dl}$ for the 20 rats after one week

\begin{tabular}{|c|c|c|}
\hline Number of Rats & Dose & Total cholesterol (mg/dl) \\
\hline Group(1) 1 & \multirow{5}{*}{ basal diet (mixing of tomato + cheese + bread) } & 77 \\
\hline 2 & & 80 \\
\hline 3 & & 70 \\
\hline 4 & & 76 \\
\hline 5 & & 72 \\
\hline $\operatorname{Group}(2) 1$ & \multirow{4}{*}{$\begin{array}{l}\text { High fat diet+injection With } 1.5 \mathrm{ml} / \mathrm{kg} \text { reused oil } \\
\text { (butter+egg+powder Cholesterol) }\end{array}$} & 85 \\
\hline 2 & & 88 \\
\hline 4 & & 85 \\
\hline 5 & & 79 \\
\hline Group(3) 1 & \multirow{5}{*}{$\begin{array}{l}\text { High fat diet+injection With } 3.0 \mathrm{ml} / \mathrm{kg} \text { reused oil } \\
\text { (butter+egg+powder Cholesterol) }\end{array}$} & 79 \\
\hline 2 & & 88 \\
\hline 3 & & 89 \\
\hline 4 & & 90 \\
\hline 5 & & 85 \\
\hline 2 & \multirow{4}{*}{ High fat diet (butter+egg+powder Cholesterol) } & 86 \\
\hline 3 & & 79 \\
\hline 4 & & 78 \\
\hline 5 & & 69 \\
\hline
\end{tabular}

Table 3. Cholesterol level in $\mathrm{mg} / \mathrm{dl}$ for the 20 rats after two weeks

\begin{tabular}{|c|c|c|}
\hline Number of Rats & Dose & Total. Cholesterol (mg/dl) \\
\hline Group(1) 1 & \multirow{5}{*}{ basal diet (mixing of tomato+cheese+bread) } & 77 \\
\hline 2 & & 81 \\
\hline 3 & & 72 \\
\hline 4 & & 76 \\
\hline 5 & & 74 \\
\hline Group(2) 1 & \multirow{5}{*}{$\begin{array}{l}\text { High fat diet }+ \text { injection With } 1.5 \mathrm{ml} / \mathrm{kg} \text { reused oil } \\
\text { (butter+egg+powder Cholesterol) }\end{array}$} & 95 \\
\hline 2 & & 92 \\
\hline 3 & & 89 \\
\hline 4 & & 92 \\
\hline 5 & & 86 \\
\hline Group(3) 1 & High fat diet + injection With $3.0 \mathrm{ml} / \mathrm{kg}$ reused oil & 69 \\
\hline
\end{tabular}




\begin{tabular}{lll}
\hline Number of Rats & Dose & Total. Cholesterol (mg/dI) \\
\hline 2 & (butter+egg+powder Cholesterol) & 102 \\
3 & & 110 \\
4 & & 114 \\
5 & & 105 \\
Group(4) 1 & & 87 \\
2 & High fat diet (butter+egg+powder Cholesterol) & 92 \\
3 & & 86 \\
4 & & 84 \\
5
\end{tabular}

Table 4. Cholesterol level in $\mathrm{mg} / \mathrm{dl}$ for the 20 rats after three weeks

\begin{tabular}{|c|c|c|}
\hline Number of Rats & Dose & Total. Cholesterol(mg/dl) \\
\hline Group(1) 1 & \multirow{5}{*}{ basal diet (mixing of tomato + cheese + bread) } & 75 \\
\hline 2 & & 80 \\
\hline 3 & & 72 \\
\hline 4 & & 77 \\
\hline 5 & & 73 \\
\hline Group(2) 1 & \multirow{4}{*}{$\begin{array}{l}\text { High fat diet }+ \text { injection With } 1.5 \mathrm{ml} / \mathrm{kg} \text { reused oil } \\
\text { (butter+egg+powder Cholesterol) }\end{array}$} & 112 \\
\hline 3 & & 114 \\
\hline 4 & & 118 \\
\hline 5 & & 115 \\
\hline Group(3) 1 & \multirow{5}{*}{$\begin{array}{l}\text { High fat diet +injection With } 3.0 \mathrm{ml} / \mathrm{kg} \text { reused oil } \\
\text { (butter+egg+ powder Cholesterol) }\end{array}$} & 121 \\
\hline 2 & & 125 \\
\hline 3 & & 128 \\
\hline 4 & & 132 \\
\hline 5 & & 127 \\
\hline Group(4) 1 & \multirow{5}{*}{ High fat diet (butter+egg+powder Cholesterol) } & 97 \\
\hline 2 & & 102 \\
\hline 3 & & 102 \\
\hline 4 & & 89 \\
\hline 5 & & 110 \\
\hline
\end{tabular}

Table 5. Cholesterol level of the 20 rats after four weeks.

\begin{tabular}{|c|c|c|}
\hline Number of Rats & Dose & Total. Cholesterol (mg/dl) \\
\hline Group(1) 1 & \multirow{5}{*}{ basal diet (mixing of tomato+cheese+bread) } & 76 \\
\hline 2 & & 80 \\
\hline 3 & & 74 \\
\hline 4 & & 78 \\
\hline 5 & & 73 \\
\hline Group(2) 1 & \multirow{5}{*}{$\begin{array}{l}\text { High fat diet +injection With } 1.5 \mathrm{ml} / \mathrm{kg} \text { reused oil } \\
\text { (butter+egg+powder Cholesterol) }\end{array}$} & 154 \\
\hline 2 & & 158 \\
\hline 3 & & 169 \\
\hline 4 & & 178 \\
\hline 5 & & 182 \\
\hline $\operatorname{Group}(3) 1$ & \multirow{5}{*}{$\begin{array}{l}\text { High fat diet +injection With } 3.0 \mathrm{ml} / \mathrm{kg} \text { reused oil } \\
\text { (butter+egg+powder Cholesterol) }\end{array}$} & 224 \\
\hline 2 & & 216 \\
\hline 3 & & 226 \\
\hline 4 & & 223 \\
\hline 5 & & 234 \\
\hline Group(4) 1 & \multirow{5}{*}{ High fat diet (butter+egg+powder Cholesterol) } & 114 \\
\hline 2 & & 120 \\
\hline 3 & & 117 \\
\hline 4 & & 118 \\
\hline 5 & & 131 \\
\hline
\end{tabular}




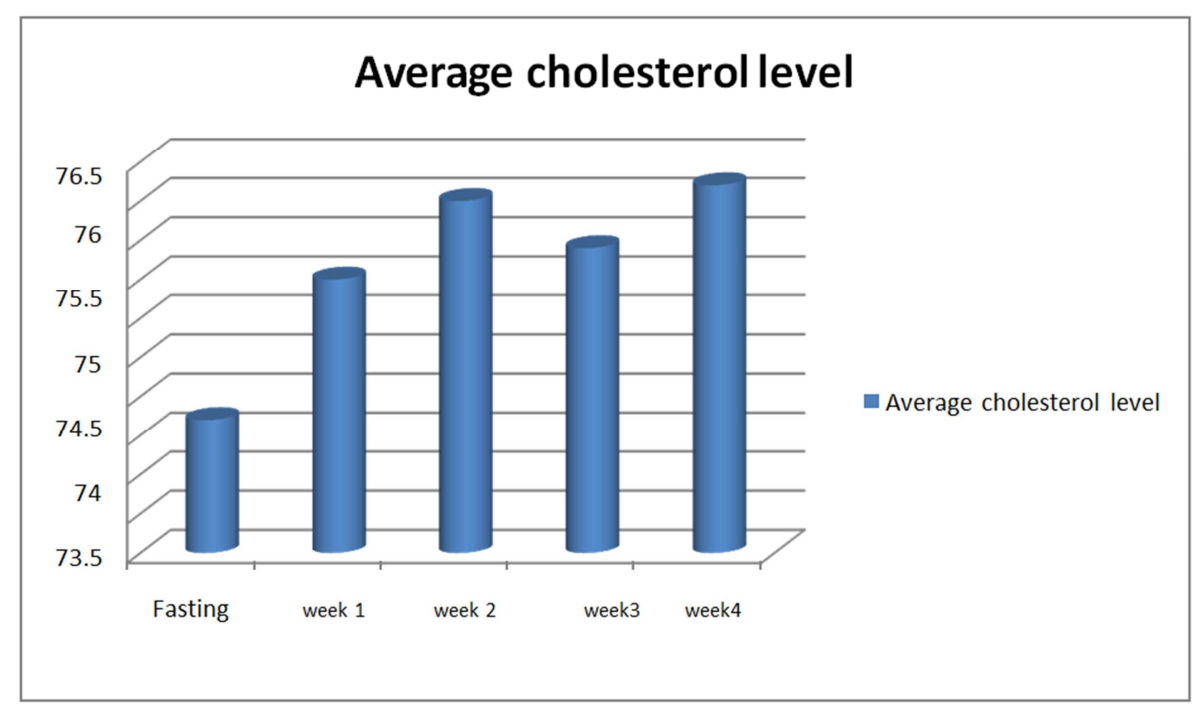

Figure 1. Variation of average cholesterol level with the consecutive period in weeks for group 1 rats.

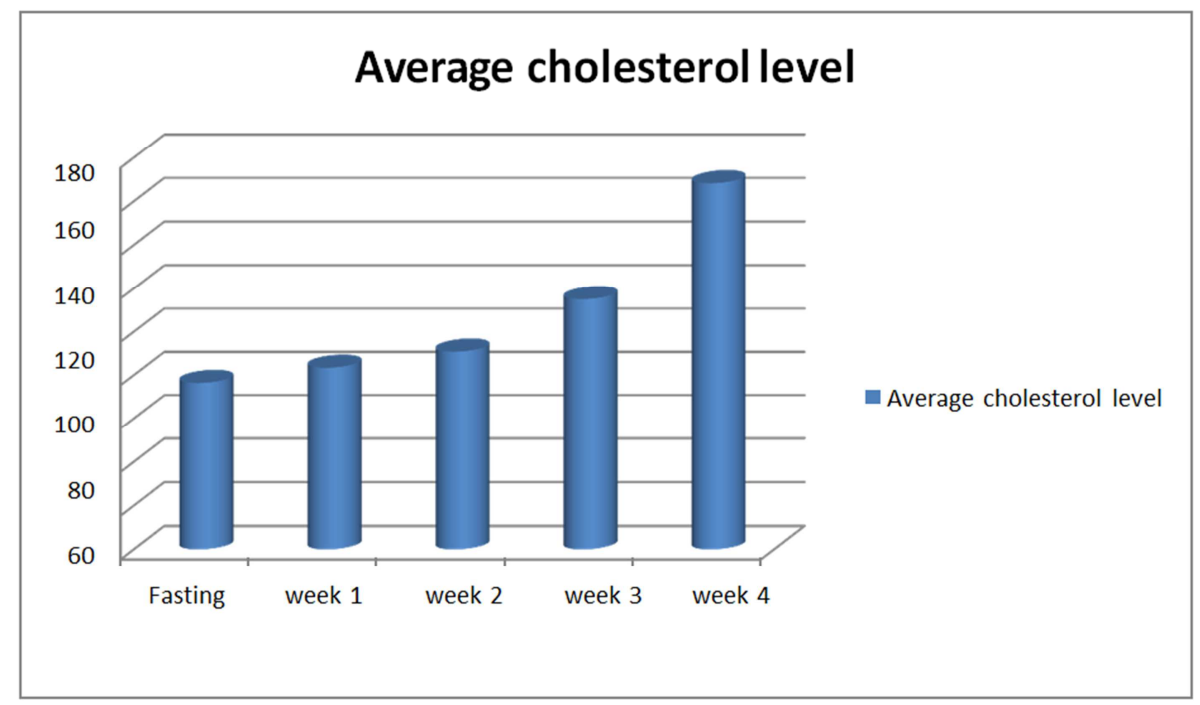

Figure 2. Variation of average cholesterol level with the consecutive period in weeks for group 2 rats.

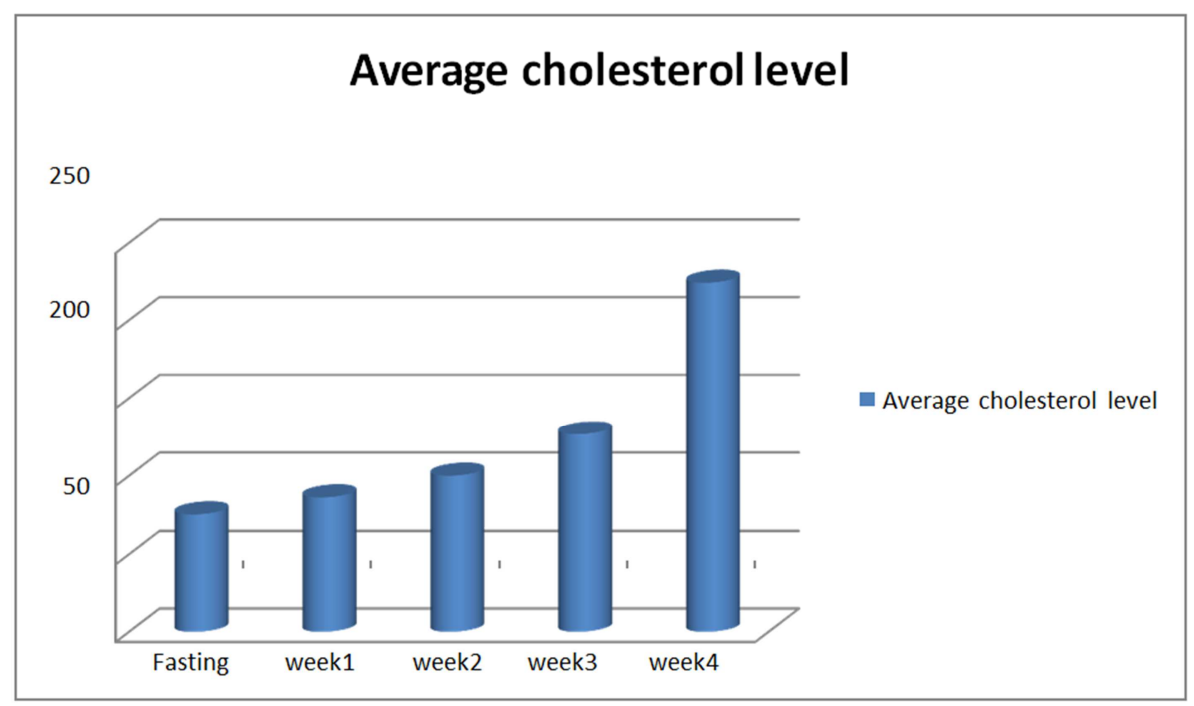

Figure 3. Variation of average cholesterol level with the consecutive period in weeks for group 3 rats 


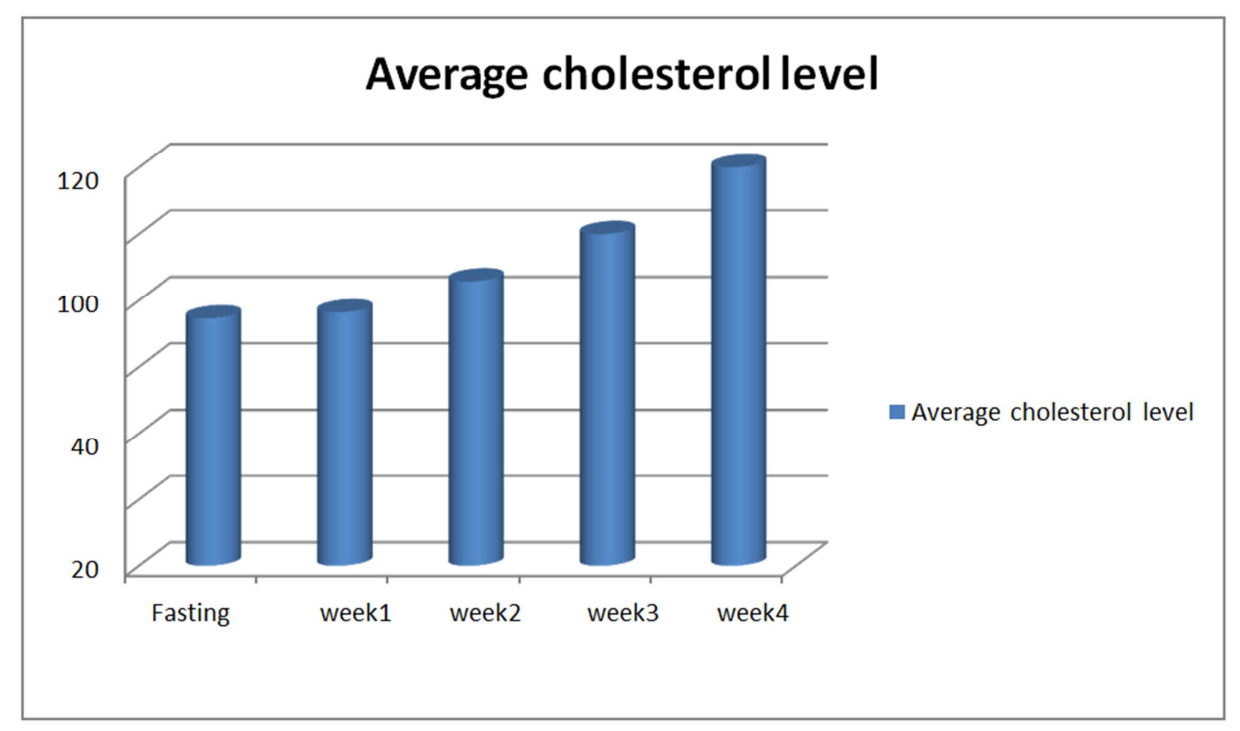

Figure 4. Variation of average cholesterol level with the consecutive period in weeks for group 4 rats.

\section{Discussion}

Adoption the blood cholesterol level in the normal range is one of the most important issues of the world health community. Elevation of the cholesterol level in the blood may lead to many vital health problems such as cardiovascular diseases, strokes, high blood pressure and diabetes.

Many reasons cause enhancement of the blood cholesterol level; one of these reasons is the usage of the reused cooking oil during frying.

This research project work covers the problem of using reused cooking oil relating to the blood cholesterol level change. Twenty rats were divided into four groups (each group consists of five rats), these groups were classified as group1 (normal diet rats), group 2 (high fat diet with 1.5 $\mathrm{ml} / \mathrm{kg}$ reused oil injection), group3 (high fat diet with $3 \mathrm{ml} / \mathrm{kg}$ reused oil injection) and group 4 (high fat diet). Cholesterol level was measured for each one of these rats separately on a fasting condition. The rats were then fed with a proper diet and injected with a dose of reused oil according to their groups; cholesterol level was measured for the twenty rats once a week for four weeks

Concerning the average cholesterol level of group 1 rats, it ranges from 73.2 during the fasting period to $75,76,65.4$ and $76.2 \mathrm{mg} / \mathrm{dl}$ for the consecutive four weeks respectively (table 1). Here we observed a narrow range of cholesterol level elevation (figure 1) and this is expected since the rats of this group were fed with a normal diet and have not being subjected to any external factors or injections to increase the cholesterol level.

Group 2 rats showed a considerable range of average cholesterol level elevation, the fasting period $=76.4$, week 1 $=83.4$, week $2=90.8$ week $3=115$ and week $4=168 \mathrm{mg} / \mathrm{dl}$. (table 2). This wide range (figure 2) is also expected since the rats of this group were feed with a high cholesterol diet and being injected with $1.5 \mathrm{ml} / \mathrm{kg}$ reused frying oil (considered as a low dose).

For rats of group 3 we expect a significant average cholesterol level elevation starting from the fasting period 75.4 up to the fourth week $224.6 \mathrm{mg} / \mathrm{dl}$ (table 3), as the rats of this group were injected with $3 \mathrm{ml} / \mathrm{kg}$ (considered as a high dose) reused oil in addition to the high cholesterol diet and this is exactly what we observed (figure 3 ).

The average cholesterol level of group 4 rats was moderately elevated starting from 74.6 on the fasting period up to $120 \mathrm{mg} / \mathrm{dl}$ on the fourth week. These rats have not being injected with a source of the reused oil and hence the elevation was not pronounced (figure 4). This result is considered as clear evidence to prove the effect of the reused oil on cholesterol level elevation.

\subsection{Conclusions}

Comparing the results of the average cholesterol level elevation in group 2 and group 3 we concluded that increasing the dose of the reused oil has a vital role on the blood cholesterol level enhancement.

\subsection{Recommendations}

1. Using the edible oil only one time for frying if possible.

2. If necessary a good compromise should be made between the financial conditions of the person and the number of times that the oil is reused specially in the developing poor countries.

3. Doing a regular blood cholesterol level check.

\section{References}

[1] Lipid bilayer." Wikipedia. 7 December 2012. 7 December $2012<$ http://en.wikipedia.org/wiki/Lipid_bilayer>.

[2] Chow, Ching Kuang, (2001). Fatty Acids in Foods and Their Health Implications. New York: Routledge Publishing. OCLC 25508943. 
[3] Lee S. A., Whenham N., Bedford M. R. Review on docosahexaenoic acid in poultry and swine nutrition: Consequence of enriched animal products on performance and health characteristics. Anim. Nutr. 2019;5:11-21. doi: 10.1016/j.aninu.2018.09.001.

[4] Alfred Thomas (2002). "Fats and Fatty Oils". Ullmann's Encyclopedia of Industrial Chemistry. Ullmann's Encyclopedia of Industrial Chemistry. Weinheim: Wiley-VCH. doi:10.1002/14356007.a10_173. ISBN 3527306730.

[5] DonaldVort, Judith G. Voet. (2011). BIOCHEMISTRY, 4, 392-393.

[6] Peter A., Kathleen M. (2009). Harper's Illustrated Biochemistry, 28, 121-124.

[7] Sidhu, D.; Naugler, C. (2012). "Fasting Time and Lipid Levels in a Community-Based Population: A Cross-sectional Study $/$
Fasting Time and Lipid Levels". Archives of Internal Medicine. 172, 22.

[8] www.heart.org/HERTORG/CONDITIONS/Cholesterol.

[9] "Sunflower oil production in 2014; Crops processed/Regions/Production quantity. United Nations Food and Agriculture Organization, Statistics Division (FAOSTAT). 2017. Retrieved 16 February (2017).

[10] https://www.ncbi.nlm.nih.gov/pmc/articles/PMC3336919.

[11] http://www.scholarsresearchlibrary.com/articles/changes-inthe-blood-lipid-profile-of-wistar-albino-rats-fed-richcholesterol-diet.pdf.

[12] H.-Y. Hsieh, L.-H. Li, R.-Y. Hsu, W.-F. Kao, Y.-C. Huang, C.C. HsuQuantification of endogenous cholesterol in human serum on paper using direct analysis in real time mass spectrometry Anal Chem, 89 (2017), pp. 6146-6152. 